\title{
Editorial
}

\section{A pesquisa sobre Agricultura Familiar no Brasil - aprendizagens, esquecimentos e novidades}

\author{
Paulo André Niederle ${ }^{1}$, Marco Antônio Verardi Fialho² e \\ Marcelo Antônio Conterato ${ }^{3}$
}

\section{O que comemorar no Ano Internacional da Agricultura Familiar?}

Ao longo dos últimos 20 anos, o Brasil presenciou a emergência de uma nova categoria sociopolítica no meio rural. Como resultado de uma confluência única de fatores, a agricultura familiar nasceu das lutas por reconhecimento e direitos empreendidas por uma miríade de atores, especialmente pelos movimentos sindicais do campo. Respondendo aos efeitos dos processos de globalização, abertura comercial, crise econômica e esfacelamento da capacidade de intervenção do Estado, e legitimados por inúmeros estudos que apontavam para o protagonismo das agriculturas de base familiar para sustentar a produção e a geração de emprego e renda em inúmeros países, esses movimentos passaram a reivindicar políticas diferenciadas de desenvolvimento rural. Desde então, inúmeras conquistas podem ser elencadas para exemplificar o que temos a comemorar neste Ano Internacional da Agricultura Familiar.

Nem o mais otimista líder sindical presente em Brasília em maio de 1994, no primeiro Grito da Terra Brasil, poderia imaginar que a Agricultura Familiar se tornaria uma categoria reconhecida e legitimada pelo Estado e pela Sociedade tal qual presenciamos atualmente, incluindo a produção de um quadro normativo específico para delimitá-la (Lei no 11.326/2006). É certo que um balanço das conquistas alcançadas não será tão otimista com relação ao conjunto das deman-

1. Professor do Departamento de Sociologia da Universidade Federal do Rio Grande do Sul. E-mail: pauloniederle@gmail.com

2. Professor do Departamento de Educação Agrícola e Extensão Rural e do Programa de Pós-graduação em Extensão Rural da Universidade Federal de Santa Maria. E-mail: marcoavf@hotmail.com

3. Professor do Departamento de Economia e Relações Internacionais e do Programa de Pós-graduação em Desenvolvimento Rural da Universidade Federal do Rio Grande do Sul. E-mail: marcelo.conterato@ufrgs.br 
das apresentadas há duas décadas: reforma agrária, crédito agrícola, preservação ambiental, direitos sociais e trabalhistas, previdência social e saúde, política energética. Mas não há como deixar de mencionar os avanços que podem ser celebrados. Neste período, o Brasil construiu uma política consistente de crédito rural diferenciado, ampliou significativamente o alcance da previdência social rural e, mais recentemente, inovou em programas que passaram a servir de exemplo para todo o mundo, em particular no que diz respeito à segurança alimentar. "Contra a fome e a miséria e pelo emprego", as palavras de ordem do primeiro Grito da Terra Brasil parecem ter ecoado ao longo dos últimos 20 anos.

Por outro lado, talvez nem o mais pessimista estudioso da agricultura familiar imaginasse naquele momento que, 20 anos depois, a sociedade brasileira continuaria presenciando graves situações de privação de direitos e liberdades no meio rural, como aquela que se expressa na submissão dos trabalhadores rurais às condições de trabalho escravo contemporâneo; conviveria com índices ainda elevados de violência no campo, fruto das resistências que se impuseram às políticas trabalhistas e de reforma agrária; vivenciaria uma crise de saúde pública em decorrência de mudanças radicais nos padrões de consumo alimentar; suportaria práticas agrícolas danosas ao meio ambiente e à saúde, em particular o fato de termos assumido a dianteira mundial no uso de agrotóxicos; e, de modo mais amplo, conviveria com inúmeros dilemas políticos que bloqueiam as tentativas de reforma institucional do Estado, criando barreiras ao aprofundamento dos processos democráticos e, portanto, ao efetivo reconhecimento dos diferentes grupos sociais que povoam o rural brasileiro.

Agora, no bojo das discussões sobre o Ano Internacional da Agricultura Familiar, essa trajetória tem sido objeto de novas reflexões analíticas e políticas. Obviamente, também contribuiu para isto a disputa aberta pela eleição presidencial, que trouxe à tona novos questionamentos e projetos. Tudo isso formou um caldo de cultura propício para que inúmeros temas que povoaram os debates agrários nas últimas décadas fossem retomados e colocados à prova de novas elaborações teóricas e de novos dados empíricos, propiciados, sobretudo, pela base de informações dos Censos Agropecuários, especialmente o de 2006. Assim, o ano de comemoração também se tornou a ocasião de uma intensa reflexão sobre o passado, o presente e o futuro da agricultura familiar e do mundo rural. Nessa discussão, como revelam inúmeros artigos que compõem este número especial, fica de antemão evidente que a compreensão da agricultura familiar, tendo em vista sua própria natureza enquanto categoria sociopolítica, não pode ser desconectada da trajetória das políticas públicas e da intervenção do Estado.

No entanto, os debates em curso não apenas avaliam a intervenção do Estado e a magnitude das mudanças socioeconômicas que a agricultura familiar experimentou desde seu reconhecimento institucional, mas, e de modo ainda mais radical, a própria pertinência da noção "agricultura familiar" para dar conta da diversidade e do modus operandi das categorias sociais que habitam o meio rural de um país com expressiva heterogeneidade sociocultural. Na última década, uma das principais novidades desta discussão foi a expansão das lutas por reconhecimento empreendidas por inúmeras populações e comunidades tradicionais que, integrando a agricultura familiar, reivindicam um olhar específico do Estado e da 
Sociedade (quilombolas, faxinalenses, geraizeiros, lavradores, ribeirinhos, indígenas, pescadores artesanais etc.). Estaríamos diante de uma crise da identidade que se configurou a partir da noção de agricultura familiar? Ou, ao contrário, as lutas desses grupos contribuem à construção de modelo diferenciado de desenvolvimento rural que tem esteio em múltiplos estilos de agricultura familiar?

$\mathrm{Na}$ academia, este momento tem se mostrado particularmente propício a novas reflexões teóricas. De modo geral, os avanços que o meio rural experimentou em decorrência do reconhecimento da agricultura familiar e do desenvolvimento de políticas públicas específicas permitiram reverter ou amenizar o processo de expulsão acelerada das famílias do campo, mas sem conseguir dar conta de outras transformações em curso, tais como as questões demográficas que envolvem a redução das taxas de fecundidade e a sucessão no meio rural. Ademais, renascem interpretações teóricas que, enfatizando as tendências mais globais do desenvolvimento agrícola (preeminência de um modelo agroexportador centrado na produção de commodities), questionam a capacidade de resiliência da 'pequena agricultura'. Assiste-se, inclusive, ao renascimento de certa convergência entre o referencial da modernização e as teorias marxistas sobre o fim dos camponeses, ressuscitando questionamentos sobre a situação subordinada dos pequenos agricultores, fadados a manter-se na periferia das grandes transformações do campo.

No período recente, inúmeras teses voltaram a discutir os limites da pequena agricultura familiar, sobretudo no que tange à composição do montante da produção agropecuária nacional. Em vista do aprofundamento de um processo de concentração econômica da produção, algumas teses passaram, inclusive, a questionar a "insistência" do Estado em direcionar políticas (supostamente) equivocadas para agricultores com baixa capacidade produtiva. A partir de uma análise da heterogeneidade estrutural que marca a agricultura brasileira, essas teses apontam para a incapacidade dos segmentos mais empobrecidos em se tornarem "verdadeiros agricultores", co-responsáveis pelo dinamismo da moderna agropecuária. A "vocação produtiva" estaria confinada a uma pequena parcela de agricultores familiares capitalizados - cujas lógicas produtivas já não seriam tão diferentes da empresa agrícola moderna -, restando aos demais somente o acesso a um conjunto de políticas sociais que os manteria fora das estatísticas da fome e da pobreza, mas não os permitiria progredir economicamente.

As antíteses desse debate constituem-se a partir da defesa de uma mudança nos parâmetros da análise sobre a capacidade de reprodução social dos agricultores familiares, associada a um questionamento sobre os referenciais que orientam a ação do Estado. Assim, sem desconsiderar a precariedade dos meios de vida desse contingente nada desprezível de pessoas, por um lado, aponta-se para a capacidade dos mesmos em construir seus meios de vida a partir de alternativas que os estudos rurais ainda não conseguiriam captar adequadamente, incluindo, por exemplo, o papel das ocupações e rendas não agrícolas, a construção de novos modelos organizacionais, o desenho de sistemas produtivos ecologicamente intensivos e a capacidade das instituições que os representam de qualificar cada vez mais suas demandas e influenciar políticas públicas específicas. Por outro lado, sustenta-se a necessidade de readequar as políticas com vistas 
a reconhecer as particularidades de agricultores que precisam encontrar novas alternativas de inclusão produtiva. Neste caso, faz-se questão de apontar o fracasso da opção modernizante mais convencional, herdeira da Revolução Verde, que, como uma profecia que se autorrealiza, estaria efetivamente contribuindo para o ocaso de uma parcela de pequenos estabelecimentos rurais, incapazes de gerar rendas monetárias significativas para responder à 'tesoura de preços' dos mercados agrícolas.

Uma síntese dessa discussão ainda está distante do horizonte dos debates contemporâneos. É possível que ela nunca seja alcançada em vista dos pressupostos que orientam diferentes concepções do mundo rural. De todo modo, talvez o próprio debate seja mais relevante do que a síntese. É neste sentido que propomos este número especial da RESR. A ocasião aberta pelo AIAF apenas somou-se à oportunidade de apresentar para um público mais amplo as discussões que a Sociedade Brasileira de Economia, Administração e Sociologia Rural tem tido o privilégio de vivenciar em seus congressos, em particular no grupo Agricultura Familiar e Ruralidades que, atualmente, temos a honra de coordenar. Somam-se a isso os inúmeros debates efetuados nos demais grupos de trabalho da própria SOBER, além de outros fóruns, associações e redes acadêmicas que contribuem para um esforço coletivo na conformação de um campo de estudos sobre a agricultura familiar no Brasil.

Neste editorial, um pouco mais extenso do que de costume, procuramos sumarizar alguns temas que rondaram os debates sobre a agricultura familiar ao longo deste período. Obviamente o texto não possui qualquer pretensão de exaurir a discussão e, como sempre ocorre nestes casos, convive com o risco da omissão de questões relevantes, para o que nos desculpamos antecipadamente. Nos artigos que compõem este número especial o leitor seguramente encontrará uma análise mais apurada de vários desses temas, a partir do olhar multidisciplinar desenvolvido por alguns dos principais estudiosos da agricultura familiar, oriundos de diferentes regiões brasileiras.

\section{O que aprendemos sobre a Agricultura Familiar nos últimos 20 anos}

Existe uma longa tradição de estudos rurais que precede a discussão sobre agricultura familiar. Não temos pretensão e condições de voltar aos mesmos neste momento. Mas é necessário reconhecer que as compreensões e reflexões sobre as dinâmicas econômicas, sociais, culturais e ambientais na agricultura familiar estão amplamente balizadas pelos debates que se produziram ao longo de diferentes momentos das ciências sociais brasileiras, abarcando distintas temáticas: questão agrária (Alberto Passos Guimarães, Gilberto Paim, Ignácio Rangel, Caio Prado Jr.); progresso técnico e inovação na agropecuária (Mario Possas, Ruy Muller Paiva, Sergio Salles Filho); reprodução social do campesinato (Antonio Cândido, Maria Isaura Pereira de Queiróz, Maria de Nazareth Baudel Wanderley); história agrária, política e movimentos sociais do campo (Gilberto Freire, Sergio Buarque de Holanda, Maria Yeda Linhares, José de Souza Martins); modernização da agri- 
cultura e seus efeitos (Geraldo Muller, Rodolfo Hoffman, Angela Kageyama, José Graziano do Silva).

Esse conjunto de autores, e tantos outros que não temos condições de elencar aqui, abriu caminho para as análises contemporâneas sobre a agricultura familiar e o mundo rural. No entanto, para encurtar a história, pode-se afirmar que, na esteira dos movimentos sociopolíticos que levaram à institucionalização da agricultura familiar, os debates travados entre os anos 1940 e 1980 sofreram uma inflexão fundamental na década seguinte. No mundo acadêmico, sob a influência de discussões que se processavam no âmbito internacional, alguns pesquisadores brasileiros se apropriaram de uma noção emergente para reestruturar o olhar analítico sobre aquelas pessoas que outrora eram a expressão de uma agricultura inconforme aos preceitos da modernidade. Assim, a institucionalização da agricultura familiar no âmbito do Estado foi retroalimentada, em uma via de mão dupla, por processos de reconhecimento e positivação teórica. Enquanto camponês, colono, meeiro, parceiro, lavrador, pequeno produtor e tantas outras designações regionais foram equivocadamente tomadas como expressão de uma agricultura atrasada em vias de extinção, a agricultura familiar emergia como identidade aglutinadora de uma forma social de produção funcional ao moderno capitalismo agrário.

Ainda que não exclusivamente, haja vista que a economia seguiu fortemente influenciada pelo referencial neoclássico associado às teorias da modernização e do difusionismo desenvolvidas por Theodore Schultz, Everett Rogers, Vernon Ruttan, Yujiro Hayami, Pitirim Sorokin e Charles Galpin, a discussão brasileira sobre agricultura familiar constitui-se principalmente sob a influência, por um lado, do debate anglo-saxão entre perspectivas neomarxistas e neochayanovianas (Kostas Vergopoulos, Suzan Mann, David Goodman, Harriet Friedman, Terry Marsden, Jan Douwe van der Ploeg, Theodore Shanin, Henry Bernstein, Bill Friedland, Anthony Fuller, Terence Byres) e, por outro, com um estreito diálogo com a literatura sobre sociedades camponesas, que marcou, sobretudo, a sociologia e a antropologia francófonas (Henry Mendras, Eric Wolf, Bernard Kayser, Marcel Jolivet, Bruno Jean, Hugues Lamarche). Do encontro entre esses mundos surgiram algumas das principais teorias lidas e discutidas nos programas brasileiros de pós-graduação voltados aos estudos rurais.

Nos anos 1990, enquanto no âmbito político-institucional uma série de movimentos reivindicava um novo olhar com relação à realidade dos pequenos produtores, na academia produziam-se alguns estudos que iriam reorientar não apenas a ação do Estado, mas nossa própria compreensão sobre o lugar e a importância da agricultura familiar. Dentre esses estudos, pode-se destacar a pesquisa comparativa internacional coordenada por Hugues Lamarche (1993), da qual participaram vários pesquisadores brasileiros; o livro de José Eli da Veiga (1991) abordando o desenvolvimento agrícola desde uma perspectiva histórica, a tese de Ricardo Abramovay (1993) revelando a agricultura familiar como base do capitalismo agrário moderno nos países desenvolvidos e, em particular, o estudo FAO-Incra (1994), Diretrizes de Política Agrária e Desenvolvimento Sustentável, coordenado por Carlos Guazirolli, e que, envolvendo um grupo de pesquisadores com importante interlocução com os gestores públicos, desempenhou papel central na for- 
matação das políticas para a agricultura familiar que começaram a ser desenhadas naquele momento.

A novidade trazida por esses estudos, conjugada a uma série de mudanças políticas em curso nos anos 1990, fez com que o Estado incorporasse um novo referencial de desenvolvimento rural. O resultado do diálogo entre academia, governo e movimentos sindicais foi a criação do Programa Nacional de Fortalecimento da Agricultura Familiar (Pronaf), cujo reconhecimento sustentou-se na capacidade da agricultura familiar em absorver a mão de obra rural e ampliar a oferta de alimentos. Desde então, inúmeras outras ações emergiram de modo mais ou menos vinculado ao crédito rural diferenciado. Criou-se, com isso, um pool de políticas que, como analisado por diversos artigos neste número especial, se tornou fundamental para garantir a reprodução da agricultura familiar, ao mesmo tempo em que abriu um enorme campo de pesquisas para os estudiosos rurais.

Como já afirmamos acima, não há como negar que a discussão em torno da reprodução da agricultura familiar foi desde o início marcada por uma preocupação com os mecanismos de ação pública. Mas, nos anos 1990, em pleno contexto neoliberal, a capacidade efetiva de intervenção do Estado era reduzida, de modo que as principais análises sobre os efeitos das políticas para a agricultura familiar serão publicadas algum tempo depois, sobretudo na década seguinte.

Naquele momento, para além da discussão mais ampla que envolveu a legitimação social da agricultura familiar (não apenas mostrar que ela não estava em uma via irreversível de extinção, mas que possuía contribuições importantes ao desenvolvimento rural), as discussões privilegiaram dois temas. O primeiro está associado ao chamado "novo mundo rural", que não deixou de ter uma estreita relação com a intervenção do Estado. Mas, neste caso, a discussão extrapolou para temas que suscitaram uma análise mais complexa das dinâmicas socioeconômicas emergentes na agricultura familiar. Neste ínterim cabe sublinhar a importância do Projeto Rururbano coordenado por José Graziano da Silva. Foi no seio do mesmo que inúmeros pesquisadores provocaram importantes inovações na agenda de pesquisas dos estudos rurais, em particular no que diz respeito às análises das ocupações não agrícolas, da agricultura a tempo parcial e da pluriatividade no meio rural. Abarcando uma série de estudos regionalizados, o Projeto Rurbano revelou a importância das estratégias não agrícolas para a resiliência da agricultura familiar.

O segundo conjunto de estudos que ganhou evidência neste momento foi aquele que pautou o tema da reforma agrária. Em face da centralidade dessa discussão nos anos 1990, vários pesquisadores dedicaram esforços para analisar questões associadas à estrutura agrária, à distribuição da propriedade e ao impacto das políticas de reforma agrária; a especificidade das dinâmicas de reprodução social que se constituía nos projetos de assentamento; os enfrentamentos políticos envolvidos nas lutas pela terra e as consequências dos processos de desterritorialização e reterritorialização dos pequenos agricultores. Com efeito, em grande parte desta década, a questão da terra ocupou não apenas o espaço da política institucionalizada, mas a agenda de inúmeros grupos de pesquisa. As diferentes conclusões a que os estudos chegaram, somadas às distintas posições políticas que 
foram se estabilizando dentro e fora da academia, logo revelaram que o tema era objeto de vívidas controvérsias, muitas das quais perduram até hoje, em que pese o cenário da discussão tenha se alterado substancialmente.

Para além desses dois temas centrais, deve-se reconhecer nos anos 1990 a profusão de uma agenda muito mais ampla de discussões sobre as dinâmicas da agricultura familiar. De forma mais ou menos associada aos debates sobre a questão da terra, emergiram inúmeras pesquisas sobre o papel dos movimentos sociais do campo em vista do novo contexto de abertura democrática. Esses debates focalizaram aspectos das lutas camponesas na historiografia agrária, a ação dos tradicionais movimentos de luta pela terra e a emergência do novo sindicalismo rural, a política local e as formas de reprodução das oligarquias e do poder nos pequenos municípios rurais, bem como discussões mais abrangentes sobre mudanças nos processos democráticos, participação social e a política institucionalizada.

Ao mesmo tempo, à medida que a agricultura familiar afirmava-se e conquistava espaço enquanto segmento produtivo no meio rural, inúmeros pesquisadores começaram a dedicar esforços para analisar o lugar destes produtores nos modernos mercados agrícolas e as consequências da reestruturação do sistema agroalimentar em um contexto de globalização. Nesta discussão, um longo e inacabado debate foi desencadeado sobre os possíveis caminhos que a agricultura familiar poderia trilhar no que tange ao mundo dos mercados, seja a via da entrada (subordinada) nas cadeias globais de valor, seja a inserção (limitada) em novos mercados de nicho e especialidades. Junto a isso se constituiu ainda o debate sobre as estratégias de especialização ou diversificação produtiva. Em face das mudanças ocasionadas, por um lado, pelo novo cenário de integração global dos mercados agrícolas e, por outro, pelas rápidas transformações na estrutura demográfica das famílias, associadas ao impacto dos processos de mecanização, um ávido debate se estabeleceu sobre as alternativas viáveis de reestruturação dos sistemas de produção agrícola familiares.

Este debate também foi levado à cabo por um conjunto específico de pesquisas construído a partir de uma interface muito próxima entre as ciências sociais e agrárias, e que podem ser agrupadas em torno dos conceitos de sistemas agrários ou sistemas de produção, elaborados originalmente na França por Marcel Mazoyer e Marc Dufumier e incorporados no Brasil em diferentes abordagens, cada qual com suas especificidades. A rigor, a unidade desse grupo ocorre mais precisamente em virtude do tipo de abordagem que aproxima as ciências sociais da agronomia e da administração, com vistas a analisar diferentes aspectos relacionados à organização da agricultura familiar (trabalho, gestão, produção, comercialização etc.), do que em virtude de uma temática específica.

Outros temas que tiveram igualmente um enfoque notadamente interdisciplinar são aqueles associados às discussões que emergiram na esteira dos debates sobre sustentabilidade e meio ambiente. Aqui a lista de temas, abordagens e pesquisadores não é menos diversa, abarcando desde os debates mais globais sobre agricultura familiar, sustentabilidade e economia ecológica, até as discussões sobre o modo como as formas familiares de produção constituem expressões diferenciadas das relações sociedade-natureza. Soma-se a isso uma infinidade de estudos acerca dos sistemas ecológicos ou sustentáveis de produção familiar, 
agroecologia, inovação e tecnologia. É difícil precisar, porém, o momento exato em que esses temas se consolidam nos estudos rurais. Embora eles remontem aos contramovimentos à modernização agrícola dos anos 1970, e tenham sido fundamentalmente catalisados a partir da Rio-92, a discussão em torno da sustentabilidade ambiental ganhará maior relevância a partir dos anos 2000, quando se torna incontornável a complexa relação entre questão agrária, agrícola e ambiental.

A partir dos anos 2000, os temas e pesquisadores também proliferaram em ritmo exponencial. Em vista do período transcorrido desde a criação do Pronaf, a avaliação e a análise das políticas para a agricultura familiar ganharam maior evidência, ainda mais após a instituição do Ministério de Desenvolvimento Agrário - MDA (Decreto no 3.338/2000), que definiu um órgão específico para tratar deste segmento. Em um primeiro momento, muitas vezes sob demanda da própria Secretaria da Agricultura Familiar (SAF), proliferaram estudos sobre os impactos do crédito, os quais apontaram tanto para a consolidação do Programa quando para as distorções que ele já produzia, sobretudo no que diz respeito às dificuldades de inclusão dos agricultores familiares mais pobres (o chamado Grupo B). Como transparece em vários artigos que compõem este número especial, o Pronaf se tornou o centro de um arranjo de políticas com efeitos muito diferenciados segundo o público envolvido, o que parece ser um resultado previsível em face da heterogeneidade social que caracteriza a agricultura familiar. O que não é tão previsível são as alternativas para corrigir as distorções criadas. Estaríamos diante de problemas de gestão passíveis de soluções incrementais ou precisaríamos de reformas mais profundas nos mecanismos de intervenção pública? Que alterações são pertinentes? Como garantir que elas terão o efeito esperado e não produzirão novas distorções?

Mas não é apenas o Pronaf o objeto dessas inquirições. Ao crédito vinculam-se inúmeras outras políticas que também passaram a ser objeto de controvérsia. Um destaque especial pode ser conferido à extensão rural, que retornou à pauta sobretudo por ocasião da construção da nova Política Nacional de Assistência Técnica e Extensão Rural (PNATER) e, mais recentemente, da Agência Nacional de Assistência Técnica e Extensão Rural (ANATER). De forma tão ou mais explícita que o crédito rural, os modelos de ATER sempre estiveram no topo da agenda dos debates agrários. Se, por um lado, o novo sistema descentralizado com participação direta da sociedade civil organizada na prestação de serviços ampliou o arco de alcance da extensão rural, que adentrou em segmentos mais periféricos e incorporou novas metodologias e projetos de desenvolvimento, por outro, o contexto de precariedades que marcam a ação extensionista revela os inúmeros desafios técnicos, organizacionais e institucionais que ainda precisam ser enfrentados, e para os quais há diversos modelos sendo propostos, nem todos convergindo para um mesmo referencial de intervenção pública e desenvolvimento rural.

Finalmente, como revelam alguns artigos inscritos neste dossiê, em virtude da ampliação das demandas apresentadas pelas organizações da agricultura familiar e do aprimoramento da ação do Estado - a criação de uma Secretaria de Desenvolvimento Territorial (SDT), por exemplo -, neste período também nota-se a emergência de uma segunda geração de políticas de desenvolvimento rural, a qual, diferentemente do foco estritamente produtivo agrícola e setorial que pre- 
domina no Pronaf, conjuga um enfoque territorial e, de modo mais destacado em algumas políticas, um referencial socioassistencial. Aqui podem ser incluídos desde os direitos sociais básicos até as ações de transferência direta de renda, além de uma miríade de programas voltados prioritariamente para a inclusão produtiva, o combate à pobreza e à desigualdade social. Dentre essas ações, inicialmente a Previdência Rural recebeu uma atenção privilegiada da pesquisa em face da relevância que a mesma demonstrou à dinâmica da agricultura familiar em todo o país. Mais recentemente, programas como Bolsa Família, Territórios da Cidadania, Territórios Rurais e Habitação Rural também têm ocupado um espaço de maior destaque na agenda de inúmeros pesquisadores.

Em suma, a relação quase simbiótica que se estabeleceu entre a análise e a implementação das políticas para a agricultura familiar possibilitou um processo de retroalimentação que, por um lado, favoreceu o contínuo aprimoramento das políticas e, por outro, levou a um interesse crescente do público acadêmico neste tipo de pesquisa, o que é louvável em face da necessidade de aprimorar os mecanismos de avaliação e análise dos programas de intervenção pública.

\section{O que esquecemos sobre a agricultura familiar?}

A relação entre a análise das dinâmicas da agricultura familiar e a reprogramação de políticas de desenvolvimento rural contribuiu para estabilizar uma determinada definição normativa associada às necessidades da ação do Estado, e que tem por objetivo primário orientar os gestores públicos. Estamos nos referindo à Lei n⿳0 11.326/2006, mas também às regulamentações mais específicas que determinam, por exemplo, os critérios de enquadramento ao Pronaf. Esse tipo de definição foi amplamente incorporado pela pesquisa social, mas, frequentemente, de um modo pouco reflexivo. Se, por um lado, o uso dos parâmetros da Lei da Agricultura Familiar favorece a tipificação e quantificação, por outro, ele traz consigo certo engessamento às análises e, sobretudo, limita o olhar dos estudiosos sobre os múltiplos parâmetros que podem ser utilizados para pensar a heterogeneidade do rural.

Essa confusão ocorre quando a apropriação de uma definição normativa como categoria heurística é feita sem o mínimo de vigilância epistemológica. Não há dúvidas de que a pesquisa social contribuiu para solidificar uma noção de agricultura familiar que favoreceu o reconhecimento e a positivação de um enorme contingente de atores sociais marginalizados do acesso ao Estado. Agora, talvez seja importante dar um passo atrás para recuperar a diversidade interna a esse grupo. Este movimento abriria a possibilidade, em seguida, de avançarmos dois passos à frente, para além de alguns dilemas contemporâneos. Esses dilemas expressam-se, por exemplo, na reprodução de dualismos que engessam a construção de análises mais consistentes sobre processos dinâmicos de reconstrução das identidades sociais. Identidades relacionais que são mobilizadas de acordo com o contexto nos qual os atores e grupos desenvolvem suas práticas e discursos.

Para fazer justiça com inúmeros estudiosos, temos que reconhecer que a diversidade não foi completamente esquecida, como sugere o título desta seção. 
Ao longo dos últimos 20 anos, diversos estudos centraram seus esforços justamente no escrutínio da heterogeneidade das agriculturas familiares, analisando as dinâmicas socioprodutivas e culturais, as relações de sociabilidade e reciprocidade, e os modos de vida dos grupos que habitam o meio rural brasileiro. Muitas dessas pesquisas foram produzidas ao largo da discussão mais institucionalizada em torno da categoria "agricultura familiar". Mas elas abriram temáticas que, hoje, estão colocadas no primeiro plano das principais discussões sobre o presente e o futuro desta categoria, bem como das políticas públicas de desenvolvimento rural: o reconhecimento e as dinâmicas das comunidades tradicionais e originárias; as relações de gênero e geração; os processos de envelhecimento, masculinização e sucessão; as formas de trabalho e propriedade no meio rural; os elementos de etnicidade e patrimônio condicionando os modos de produção e consumo; a produção de novas identidades associadas à emergência de novas ruralidades.

Vários desses estudos privilegiaram outras identidades sociais, algumas das quais assumem um conteúdo heurístico específico a depender da abordagem teórica que orienta a pesquisa. Eles compartilham uma reivindicação para um olhar mais atento das ciências sociais e do próprio Estado para grupos específicos. Não apenas sugerem que a noção de agricultura familiar tem se mostrado insuficiente para identificar as dinâmicas produtivas e socioculturais presentes, por exemplo, dentre comunidades de camponeses, colonos, lavradores, ribeirinhos, quilombolas, faxinalenses e indígenas, mas, sobretudo, que existe uma diversidade significativa no interior desses grupos, o que torna imprudente algumas generalizações recorrentes tanto nas políticas públicas quanto na pesquisa social. Como tratar, por exemplo, as comunidades originárias como se todas as sociedades indígenas pudessem ser expressão de uma única identidade? Obviamente isso não se verifica.

Esse tipo de reivindicação caminha ao encontro de inúmeros argumentos já inventariados sobre os limites conceituais da noção "agricultura familiar", expostos por autores de diferentes matizes teóricos. Alguns reivindicam uma tradição consolidada nos estudos rurais brasileiros em torno da noção de campesinato. Há uma relevante discussão sobre o conteúdo heurístico e político desta categoria. Por um lado, os diferentes significados que o termo tem assumido na literatura contemporânea, nacional e internacional, configura uma das dificuldades para a construção de uma alternativa analítica à noção corrente de agricultura familiar. Entre o "modo camponês de fazer agricultura" e as "expressões socioculturais de uma campesinidade" há um hiato que ainda precisa encontrar a adequada conjunção. Por outro, o conteúdo político que o termo adquiriu nas lutas sociais permitiu aglutinar grupos heterogêneos em torno de novos modelos de agricultura e sociedade, mas, como efeito, também gerou fortes oposições, de modo que um simples significante como 'recampesinização' passou a ser significado como fato ou fábula dependendo do sujeito do discurso.

Em outra perspectiva, sobretudo dentro dos muros da economia, há quem defenda um retorno à definição de "pequena produção". Neste caso, muitas vezes em prol de um novo ciclo de modernização técnica, retrocede-se ao debate e às categorias dos anos 1980, quando este processo teria sido interrom- 
pido. É verdade que isso possibilita a criação de tipologias com fronteiras muito mais nítidas, com base em um conjunto restrito de dados quantitativos. Mas, até que ponto é pertinente tomar a diversidade como expressão pura e simples da quantidade de área ou renda que um estabelecimento rural dispõe? Poder-se-ia ainda arguir se isso não representa uma espécie de amnésia teórica no que diz respeito ao reconhecimento daquilo que os estudos rurais produziram nos últimos trinta anos, em grande medida como reação às fragilidades das concepções de commercialization e commoditization que permearam os debates entre a economia neoclássica e neomarxista.

Seja como for, o fato é que esse tipo de alternativa pode colocar em risco os avanços sociais que foram produzidos a partir do reconhecimento político e acadêmico da agricultura familiar. Ademais, isso também não contribui significativamente para a construção de uma abordagem realmente capaz de captar a heterogeneidade do rural. Exceto os estudos que preferem trabalhar com as chamadas categorias êmicas, as inovações analíticas parecem restritas a diferentes tentativas de tipificação do mundo social, as quais ocorrem ora com base em dados quantitativos a partir dos quais se geram agrupamentos de unidades produtivas, ora a partir de abordagens qualitativas que focalizam os discursos representacionais dos agricultores, explorando as múltiplas e complexas identidades sociais do rural contemporâneo. Em que pese a incipiência dessas propostas de escrutínio dos inúmeros estilos de agricultura familiar, e a pressão contínua por uma readequação aos critérios normativos, esses estudos seguramente cumprem um papel fundamental ao descortinar aspectos do mundo social que não são facilmente visíveis a um observador acostumado à frieza da definição normativa. Há, todavia, uma enorme agenda de investigações pela frente.

Essa agenda também abarca um debate particularmente intrincado que rondou os estudos rurais ao longo de todo esse período, qual seja, o dualismo agricultura familiar $x$ agronegócio. Ao mesmo tempo em que a agricultura familiar consolidou-se como categoria sociopolítica, algo similar ocorreu com o agronegócio. Os embates sociais produziram uma cisão que ainda precisa ser analisada mais cuidadosamente. No momento, duas vertentes analíticas principais sobressaem. A primeira está associada à discussão sobre a inserção da agricultura familiar no agronegócio, quando este é considerado como o conjunto das interligações que conformam uma cadeia de valor. A segunda diz respeito aos debates da sociologia política que reconhecem agricultura familiar e agronegócio como identidades sociopolíticas que articulam grupos com interesses e valores distintos, a partir dos quais se opõem diferentes projetos de desenvolvimento. Em ambas as vertentes, soma-se ainda um conjunto de pesquisas que tem dedicado atenção à diversidade interna do agronegócio.

Por sua vez, uma novidade que tem movimentado o cenário acadêmico e institucional diz respeito à emergência de uma nova noção, cujo conteúdo preciso ainda é uma incógnita: "médio produtor rural". Já incorporada pela ação do Estado, em particular no chamado Programa Nacional de Apoio ao Médio Produtor Rural (Pronamp), a proclamada "classe média rural" tem sido adotada como expressão de um novo ator social e político. Há um risco evidente de este termo ser rapidamente incorporado pela pesquisa. Produzir um entendimento 
sobre seu significado, não apenas do ponto de vista econômico, mas da identidade sociopolítica que ele suporta, seguramente não será uma tarefa menos desafiadora e questionável.

\section{Inovações recentes nos estudos rurais}

Na última década, novas questões e pesquisadores adentraram aos estudos rurais. Junto com isso, houve um importante movimento na direção de diálogos multidisciplinares, sobretudo à medida que vários estudiosos da agricultura familiar passaram a estabelecer pontes com outras áreas de investigação. Dentre todos os temas emergentes, tornou-se de notável relevância uma discussão polifônica sobre sustentabilidade, multifuncionalidade e território. Esses três termos conjugaram uma nova caixa de ferramentas analíticas para pensar as estratégias de desenvolvimento rural e o lugar da agricultura familiar. Com efeito, proliferaram estudos sobre o rural como espaço de vida, depositário de um patrimônio ecológico e imaterial. Junto a isso, ganhou novo alento a discussão sobre ruralidades. Retomando um questionamento que remonta, pelo menos, à década de 1990, sobre as fronteiras entre o rural e o urbano, nos últimos anos uma profícua discussão foi relançada sobre as funções e medidas da ruralidade.

Outra discussão retomada com afinco é aquela sobre segurança alimentar e nutricional. Não é justo afirmar que se trata de uma completa novidade, tendo em vista os estudos clássicos de Josué de Castro, por exemplo. Porém, é importante reconhecer as inovações produzidas na última década, as quais inauguraram outro olhar sobre os papeis e a relevância das formas familiares de produção. Mais do que produzir alimentos em quantidade, a agricultura familiar também passou a ser reconhecida pela sua contribuição à soberania e segurança alimentar e nutricional, tornando-se uma opção estratégica para tentar reverter uma verdadeira epidemia na saúde pública, a qual se expressa nas inúmeras doenças que decorrem das drásticas transformações nos padrões de consumo alimentar. Esse reconhecimento está no centro de uma nova geração de políticas para a agricultura familiar, a qual se expressa, sobretudo, nos mercados institucionais. Amplamente investigados nos últimos anos, no escopo destes mercados encontra-se a novidade trazida pelo Programa de Aquisição de Alimentos (PAA) e pelo Programa Nacional de Alimentação Escolar (PNAE).

$\mathrm{Na}$ interface entre os estudos rurais, a sociologia ambiental e a economia dos recursos naturais também emergiram questões inovadoras. Em um primeiro grupo estão aqueles estudos acerca do papel da agricultura e das possibilidades e limites de inserção das unidades familiares no desenvolvimento de novos modelos de produção agroenergética, com especial destaque para os mercados de biodiesel. Um segundo grupo reúne os estudos que exploram as possibilidades abertas pelos novos mercados com foco no uso sustentável dos recursos naturais e serviços ecossistêmicos. O terceiro está associado aos estudos sobre os conflitos socioambientais que emergem a partir dos grandes investimentos em infraestrutura, sugerindo a contraposição de diferentes modelos de desenvolvimento para o meio rural em distintas regiões brasileiras. Finalmente, somam-se a isso os deba- 
tes de uma sociologia das técnicas e das ciências que coloca em relevo temas como a proteção de cultivares, a transgenia, a bio e a nanotecnologia.

Algumas inovações tem se dado por meio de uma ressiginificação de tradições bem consolidadas. Esse é o caso do debate sobre as mudanças na estrutura agrária. A discussão sobre a política de reforma agrária perdeu espaço na agenda do Estado e, consequentemente, da própria pesquisa. Mas os debates sobre a questão agrária retornaram com veemência nos últimos anos, sobretudo em vista das reestruturações globais do capitalismo. Assim, incorporam-se novos elementos à discussão sobre a propriedade e o uso da terra, agora dialogando com as discussões acerca das mudanças mais amplas do sistema agroalimentar que conjugam concentração e estrangeirização da terra, elevação dos preços da terra, novas formas de arrendamento, governança fundiária, entre outros.

Nas discussões sobre movimentos sociais rurais três temas nos parecem particularmente proeminentes nos últimos anos. Primeiro, um interesse crescente da pesquisa social com relação as interfaces entre os movimentos sociais rurais que atuam em âmbito local e suas redes internacionais. Segundo, a questão da judicialização das lutas sociais, associada à criminalização dos movimentos e organizações do campo, o que tem aberto um campo de pesquisa para a sociologia do direito. Finalmente, a ampliação dos estudos direcionados para novos movimentos socioambientais e de consumidores, os quais abrem uma janela de diálogo entre as pautas agrícolas e agrárias dos movimentos tradicionais e as preocupações contemporâneas com a sustentabilidade, a alimentação e os direitos sociais.

Por sua vez, no que diz respeito ao debate sobre mercados e agricultura familiar, ao mesmo tempo em que as novas dinâmicas das cadeias globais de commodities agrícolas chama a atenção de inúmeros pesquisadores, muitos dos quais redirecionaram o eixo das pesquisas para os novos parceiros comerciais (sobretudo a China), nota-se uma proliferação de pesquisas sobre os chamados "novos mercados alimentares". O foco desses trabalhos é a análise das condições de inserção da agricultura familiar em circuitos alternativos de comercialização que se abrem a partir da revalorização de alguns atributos do mundo rural que favorecem, por exemplo, o reconhecimento dos processos tradicionais, ecológicos, orgânicos e artesanais de produção alimentar. Os debates abordam o potencial desses mercados para constituir uma alternativa viável de inclusão produtiva, sobretudo para aqueles agricultores familiares que foram mantidos à margem das cadeias globais.

Já no âmbito das discussões sobre políticas públicas e agricultura familiar, para além do que já foi afirmado acima, um tema que chama a atenção novamente são os dilemas da interação entre Estado e Sociedade Civil, no qual está imiscuído o debate sobre as formas e os mecanismos de participação social. Esse tema tem sido reaberto em vista dos novos modelos de ação pública que projetam uma participação expressiva da sociedade civil organizada não apenas no processo de construção das políticas para a agricultura familiar, mas na própria operacionalização das mesmas, haja vista os exemplos dos programas de aquisição de alimentos, alimentação escolar, habitação rural, extensão rural e desenvolvimento territorial, dentre outros. Essa discussão traz para a ordem do dia das pesquisas, por um lado, a fragilidade dos marcos institucionais que regulamentam essa par- 
ticipação e, por outro, as possibilidades e limites dos espaços públicos, tão importantes nos anos 1990, quando vários estudos focalizaram o papel dos conselhos municipais de desenvolvimento rural.

Ainda no escopo das discussões sobre as políticas para a agricultura familiar, outro tema que surge como uma novidade recente são os estudos sobre transferência de políticas públicas. Tendo em vista o crescente protagonismo do Brasil no cenário internacional, sobretudo no tema da segurança alimentar, diversas políticas estão sendo replicadas em outros países, o que abriu um novo campo de investigações comparativas que pode contribuir decisivamente para compreender os avanços e os limites da ação do Estado.

Tanto em virtude desse diálogo aberto pelos processos de policy transfer, quanto em virtude da própria internacionalização dos movimentos sociais, nota-se igualmente uma crescente preocupação com a internacionalização dos estudos rurais. Para além da já conhecida cooperação com Europa e Estados Unidos, que, como destacamos acima, estiveram na origem dos debates sobre a agricultura familiar no Brasil, parte significativa dos novos esforços estrutura-se em torno das chamadas relações sul-sul. A iniciativa Bicas (BRICS Initiative for Critical Agrarian Studies) talvez seja o fato mais recente e inovador neste sentido. Mas há também um conjunto crescente de ações no âmbito do Mercosul e da América Latina, sejam aquelas impulsionadas pela Reaf (Reunião Especializada sobre Agricultura Familiar), sejam as iniciativas mais pontuais envolvendo parcerias entre diversos grupos de pesquisa e programas de pós-graduação.

Finalmente, nota-se ainda uma crescente preocupação das análises socioeconômicas em compreender as transformações do meio rural e, em particular, da agricultura familiar em face das mudanças mais amplas da economia brasileira e mundial. A melhoria dos indicadores socioeconômicos (nível de emprego, renda e salários, por exemplo) criou novas condições de reprodução social para os agricultores familiares, influenciando não apenas as decisões de investimento produtivo, mas também de educação dos filhos, sucessão hereditária e migração. Por mais evidente que possa parecer essa relação, ainda existem várias caixas-pretas para a pesquisa social. Quais os efeitos da melhoria ou deterioração das condições de vida nas cidades sobre a dinâmica econômica e demográfica do espaço rural? O estudo dos pequenos municípios rurais volta à agenda. Há que se analisar, por exemplo, as diferenças entre o êxodo dos agricultores para os grandes centros urbanos, que caracterizou o período da modernização conservadora, e as novas dinâmicas de migração para pequenos e médios municípios em busca de serviços e oportunidades, mas nem por isso rompendo definitivamente o vínculo com a agricultura e o meio rural.

\section{A organização deste número especial sobre agricultura familiar}

Há um leque muito grande de temas que interessam à pesquisa social sobre agricultura familiar. Nem este editorial, nem os artigos que compõem este número especial da RESR são capazes de abarcá-los em sua totalidade. Mas, os artigos deste dossiê não apenas têm o mérito de focalizar inúmeros deles, como também 
de fazê-lo de forma multidisciplinar, mobilizando os mais variados referenciais teóricos, instrumentos e métodos de pesquisa.

O dossiê é introduzido por uma reflexão sobre as lógicas constitutivas da agricultura familiar. Resistência e resiliência são os termos conjugados tanto por Maria de Nazareth Baudel Wanderley, em seu artigo focalizando a constituição do campesinato brasileiro, quanto por Amilcar Baiardi e Cristina Macêdo de Alencar, em um texto que reinterpreta formulações clássicas e contemporâneas sobre a reprodução das formas familiares de produção na agricultura. $O$ foco de ambos os textos é o lugar das formas familiares de agricultura frente às transformações das sociedades modernas.

Esta discussão é complementada pelo artigo de Everton Lazaretti Picolotto, o qual analisa o processo histórico de construção da agricultura familiar enquanto categoria identitária e ator coletivo, destacando as lutas por reconhecimento empreendidas pelos movimentos sociais e o papel do Estado na institucionalização de políticas públicas.

Em seguida, o artigo assinado por Carlos Enrique Guanziroli e Alberto Di Sabatto explora a heterogeneidade da agricultura brasileira, revelando as disparidades entre os segmentos patronais, empresariais e familiares. Os autores concluem acerca da importância da manutenção e readequação das políticas públicas para atender os diversos segmentos, e, em particular, uma readequação do Pronaf, com vistas a tratar com políticas diferenciadas o público diferenciado que compõe a agricultura familiar no Brasil.

$\mathrm{O}$ artigo de Lauro Mattei analisa criticamente um conjunto de teses recentes sobre o meio rural brasileiro. Com ampla repercussão no último ano, essas teses passaram a balizar alguns debates contemporâneos. Depois de expor cada uma das sete teses, o autor propõe uma análise crítica detalhada, procurando revelar as fragilidades e contradições das mesmas.

Catia Grisa e Sergio Schneider contribuem ao dossiê com uma leitura da trajetória de construção das políticas públicas para a agricultura familiar focalizando as relações entre Estado e sociedade civil. Os autores sugerem a existência de três "gerações" ou referenciais de políticas públicas constituídos em períodos e contextos distintos, sendo o primeiro pautado por um viés agrícola e agrário; o segundo focado em políticas sociais e assistenciais; e o terceiro pela construção de mercados orientados pela segurança alimentar e pela sustentabilidade ambiental.

Na esteira dos estudos sobre a intervenção do Estado, um conjunto de artigos explora os efeitos das principais políticas para a agricultura familiar sobre as condições de vida das famílias rurais. A partir de um modelo econométrico dinâmico para dados em painel, Henrique Rogê Batista e Henrique Dantas Neder analisam os efeitos do Pronaf sobre a pobreza rural no Brasil. Concluem que o efeito do crédito diferenciado está condicionado às especificidades socioeconômicas das unidades de observação, mas que os gastos do Programa tendem a reduzir indiretamente a pobreza via elevação da renda média e da redução da concentração de renda.

Os impactos do PronaF também são o objeto de investigação de Joacir Rufino de Aquino e Marta Aurélia Dantas de Lacerda. Com base em tabulações especiais do Censo Agropecuário, os autores discorrem sobre a dimensão e as condições 
de reprodução econômica dos agricultores pobres no estado do Rio Grande do Norte. O trabalho revela que o baixo valor da produção agropecuária é determinado por "múltiplas carências produtivas" (escassez de terra, água, educação, tecnologias, crédito e assistência técnica) que tornam a reprodução econômica dependente de outras fontes de receitas, com especial destaque para as rendas das aposentadorias rurais e programas de transferência de renda.

Dalva Maria da Mota, Heribert Schmitz, Josué Francisco da Silva Júnior e Raquel Fernandes de Araújo Rodrigues ampliam a análise para outras políticas públicas. A partir de uma abordagem qualitativa, o artigo analisa a relação entre a organização do trabalho familiar no extrativismo e a participação em programas de políticas públicas no Estado de Sergipe. O foco são as mudanças nos processos de trabalho das mulheres catadoras de mangaba e marisqueiras como efeito da ação do Programa Bolsa Família, do Seguro Desemprego do Pescador Artesanal e do Programa de Aquisição de Alimentos. As conclusões sugerem que os programas influenciam na reorganização do cotidiano do trabalho no extrativismo, na alteração dos papéis tradicionais de homens e mulheres, e mesmo na alteração dos sentidos atribuídos ao trabalho.

Os impactos das políticas para a Agricultura Familiar também são objeto de investigação de Vanilde Esquerdo e Sonia Bergamasco. No artigo, as autoras discutem o acesso ao Pronaf, ao PAA e ao PNAE pelos agricultores do chamado "Circuito das Frutas" de São Paulo. O texto sugere que, diante de um universo de agricultores mais capitalizados e inseridos nos mercados, ainda é pequena a participação dos mesmos nos programas analisados. Dentre os fatores que explicariam tal fato, nota-se a falta de informações sobre as características e possibilidades abertas pelos programas, mas também os limites do valor passível de ser acessado por esse segmento produtivo.

Finalmente, o número é encerrado por um artigo de José Antonio Herrera sobre as estratégias de produção agropecuária familiar no Sudoeste Paraense. O autor analisa os efeitos da lógica do capital sobre a exploração dos recursos naturais, enfatizando a degradação ambiental e o agravamento dos problemas sociais. Segundo o autor, a imposição do capital nas relações estabelecidas, mesmo alterando as condições de reprodução da agropecuária familiar, não a eliminou. A resiliência da mesma encontra-se na sua capacidade de estabelecer relações diferenciadas com os recursos naturais, o que justificaria maior atenção das políticas públicas ao seu fortalecimento, com vistas à construção de novos modelos de desenvolvimento rural. 